\title{
Evaluación preliminar de un nuevo test de cribado de demencia (Eurotest)
}

\author{
Comentado por: Ana Paula Machado Goyano Mac-Kay ${ }^{1}$
}

Montoro-Rios MT, Carnero-Pardo C. Evaluación preliminar de un nuevo test de cribado de demencia (Eurotest). Rev Neurol. 2004;38(3):201-9.

O diagnóstico precoce nas demências, embora complexo e custoso, é importante quando se consideram aspectos clínicos e de custo de aplicação como: qualificação e experiência dos profissionais e avaliação detalhada com uma série de provas complementares. A maioria dos sujeitos com demência é identificada na Atenção Primária e, por essa razão, seria importante contar com um instrumento capaz de ser aplicado como triagem (cribado/screening) no sentido amplo do termo, e que permita a seleção dos sujeitos para encaminhamento aos serviços especializados.

Do ponto de vista formal, os testes de triagem são de diagnóstico, porém apresentam características peculiares: seu objetivo é selecionar sujeitos para diagnóstico detalhado posterior; são aplicados em locais de baixa prevalência da doença e muitas vezes por profissionais não especializados e devem reunir determinadas condições de aplicabilidade. Quanto a este aspecto, os autores sugerem que ele deve ser simples, barato, fácil de aplicar e interpretar, utilizar materiais do cotidiano e rápido; por outro lado, seguro, agradável para o examinado e incluir a possibilidade de aplicação no maior número de sujeitos, sejam quais forem suas limitações (físicas, sensoriais ou culturais). Os testes neuropsicológicos breves são provas diagnósticas de demência que preenchem estes requisitos, visto que os testes genéticos, bioquímicos ou de neuroimagem não se adaptam a esta finalidade.

A adoção da moeda como estrutura para triagem cognitiva ocorreu por ela ser um conhecimento universal e homogêneo dentro de uma população. O Eurotest foi concebido a partir da adaptação do teste do dinheiro ao sistema monetário europeu e foi necessário o transcurso de mais ou menos dois anos para a sua implantação efetiva. Ele é uma prova neuropsicológica breve que avalia o conhecimento das moedas e bilhetes e a habilidade de memória manipuladas previamente após a introdução de uma tarefa distratora; explora de forma rápida e simples também função executiva (cálcu-

(1) Doutora em Semiótica e Linguística Geral pela Faculdade de Filosofia, Letras e Ciências Humanas da Universidade de São Paulo - USP - São Paulo (SP), Brasil; Professora Adjunto do Curso de Fonoaudiologia da Faculdade de Ciências Médicas da Santa Casa de São Paulo - FCMSCSP - São Paulo (SP), Brasil.

Endereço para correspondência: Ana Paula Machado Goyano Mac-Kay. R. Cesário Mota Jr, 61, $8^{\circ}$ andar, São Paulo - SP, CEP 01221-906. E-mail: ana.mackay@fcmscsp.edu.br lo, resolução de problemas) e coloca em evidência a capacidade para manejar o dinheiro (capacidade funcional instrumental fundamental e necessária para uma vida social independente e autônoma). Sua aplicação tem demonstrado validade similar ou superior a outros testes breves, com as vantagens: de poder ser aplicado em analfabetos, não sofrer influência da escolaridade, apresentar boa correlação com provas teste-reteste, ser bem aceito pelos pacientes e de aplicação em todos os países que adotam o euro como moeda.

$\mathrm{Na}$ Espanha, devido a um viés cultural, a assistência neurológica é prestada a uma população heterogênea, e a utilização do Eurotest permite avaliar os pacientes de forma mais eficiente e rigorosa. Segundo os autores, o objetivo deste estudo foi o de analisar as experiências dos autores com o Eurotest e compará-lo com outros testes de screening para verificar a presença de diferenças entre pacientes espanhóis e de outros da Europa.

A casuística incluiu pacientes atendidos no Departamento de Neurologia Geral do Hospital Comarcal Marina Alta de Denis, da rede pública da Comunidade Valenciana, com queixas compatíveis com transtorno cognitivo.

Foram levantados dados epidemiológicos e demográficos do grupo alvo e como critérios de inclusão foram utilizados: a pontuação na escala global de distúrbio cognitivo (GDS) entre dois e quatro, capazes de realizar o teste e interessados em participar da pesquisa; os critérios de diagnóstico estatístico (DSM-IV) para demências e transtornos psiquiátricos; a pontuação superior a oito na escala de depressão de Hamilton para os casos de transtorno cognitivo associado a transtorno depressivo; os critérios de consenso de Newcastle para os pacientes com suspeita de demência por corpos de Lewy e os critérios de Petersen et al. para os casos de transtorno cognitivo leve (TCL). Concomitante ao Eurotest foi administrado o Mini Exame do Estado Mental (MEEM) de Folstein e o teste do relógio (TR) de nove pontos. Os resultados destes três últimos testes se converteram em variável categorial, segundo o ponto de corte standard para cada um: considerou-se a presença de transtorno cognitivo para o Eurotest igual ou menor a 23, para o teste do relógio menor a sete e o MEEM ajustado por idade e escolaridade conforme Crume et al. Aos pacientes que apresentaram transtorno leve ou moderado, foi acrescentado um estudo complementar com análises de despistagem para a demência (incluindo 
hemograma, bioquímica, níveis de hormônios da tireóide, vitamina B12, ácido fólico e sorologia de lúes) e um estudo de neuroimagem com tomográfica computadorizada axial (TAC). O tratamento dos dados foi realizado pelo SPSS v.11, teste de Fischer, $t$ de Student e o $U$ de Mann-Whitney; para a concordância dos dados, o coeficiente de correlação de Pearson e o índice $x$.

Os resultados foram obtidos sobre: 45 pacientes, 21 homens e 24 mulheres, com idade média de 69 a 76 anos; 34 espanhóis e seis britânicos, cinco de outros países da zona do euro e residentes na Espanha desde antes da introdução da moeda; quanto à escolaridade, seis haviam concluído o ensino elementar, 22 o ensino fundamental completo, seis o ensino médio e 11 o ensino superior.

A distribuição segundo a pontuação pelo GDS foi de dez pacientes com transtorno associado à idade (GDS2), $18 \mathrm{com}$ DCL (GDS3) e 17 com transtorno cognitivo moderado (GDS4). Os dados gerais do estudo neuropsicológico indicaram pontuação média para o GDS de 3,16, para o Eurotest 26,19, para o MEEM de 25,84 e para o teste do relógio 7,44. $\mathrm{O}$ índice de correlação entre os testes indicou concordância moderada entre o Eurotest e os outros com índice de 0,39 para o MEEM e 0,48 para o TR.

Os autores propõem em sua discussão que a grupo alvo foi bastante heterogênea, característica da população da área geográfica em que vivem; a idade média, relativamente jovem, refletiu o fato de a seleção ter sido de pacientes em estágios precoces de queixas, com maior grau de paridade no aspecto gênero. $\mathrm{O}$ grupo de estrangeiros foi majoritariamente britânico, mas vivendo há bastante tempo na zona de moeda - euro - e, assim, expostos ao seu uso no cotidiano. $\mathrm{O}$ grande número de pacientes sem transtorno cognitivo claro nas provas neuropsicológicas refletiu a atenção precoce que a eles é prestada dentro do serviço de neurologia. A maioria dos pacientes com transtorno apresentou como causa a doença de Alzheimer e o diagnóstico mais encontrado foi o DCL, de grande utilidade clínica, embora com pouca especificidade etiológica.

Os resultados dos testes foram capazes de diferenciar de forma segura os dez pacientes que não apresentaram transtorno objetivo (GDS 2). No entanto, os dados indiciam que com o avanço do processo se pode comprovar como o MEEM é discretamente superior ao TR e o Eurotest, por sua vez, superior a ambos na medida em que diagnosticou nove pacientes com demência leve dos 17 com nível 3 da escala GDS (contra sete diagnosticados pelo MEEM e seis pelo TR). As diferenças não foram estatisticamente significativas, mas indicaram uma tendência nos dados. Não foi observada diferença entre os comportamentos do grupo espanhol com o de estrangeiros. O estudo de concordância entre os testes indicaram resultados muito semelhantes ao da literatura de referência utilizada na pesquisa.

Concluindo, os autores indicam que o Eurotest cumpre suas funções como teste de triagem, e que a correlação dos resultados dos testes, quando aplicada a pontuação de corte, foi boa embora não tão alta quanto a esperada. 